their prose is turgid, jargon-strewn and benevolently elitist; all of which are grave impediments for those they seek to convert. 'We need to talk clearly and simply and avoid jargon', they exhort but they do not. 'Ageism', 'outreach exercises', 'advocacy relationship' and much else make for a halting narrative. With one term, 'self advocate', we learn 'there is a danger that if definitions are drawn too tightly too early on, outsiders may end up setting the agendas and marking out the boundaries of what is and what might happen'. It is doubtful if this approach will breach 'the professional resistance and organisational blocks' which the authors insist 'still need to be overcome'. If words cannot express their meaning, little else is likely to.

'Many professional groups remain reluctant to share the information they have; some believe doctors alone should make decisions about patients; others are afraid of any exposure that will reveal their own levels of competence and performance.' 'Much of this information simply does not exist at present; not even in a form useful to managers and clinicians, let alone to users.' This is very true. Fashionable audit measures numbers (of days, prescriptions, referrals etc) but it has yet meaningfully to tackle quality. The measures of competence and performance (as the authors put it), are to be deduced, each time a person sees a doctor, from answers to the following questions: Has this person benefited, not benefited, or been made worse? To date, these questions are not being asked, let alone their answers made public.

Unfortunately this booklet suffers from imbalance; for while it contains, usefully, no medical prejudice, it simultaneously contains no medical insight. It holds one main belief: that if users have more information, more power to influence, then the users of the health and social services will naturally benefit. They may sometimes. But the premise is dangerously naive. Illogical though it may seem, more user information and power can and does lead to unreasonable expectations, to mistaken views of what is needed, and to servile doctors providing unnecessary items for what their patients perceive, in their increased but still incomplete awareness, as necessary. Thousands of drugs, referrals and even operations are annually and eventually shown (by the patient) to have been unhelpful (at best) - although in the short term they were the 'something' that the patient wanted and was pacified with. Does this mean that user ignorance is bliss? On the contrary. Equality between user and professional is highly desirable. But the services will become 'user friendly' (the authors' term) only when the professionals are dishabituated from practising as if by rote, under cover of 'professionalism'. Medical excellence will come from meaningful accountability which, in my view, is best carried out by professionals as well as users; perhaps, in the present absence of such an initiative, by a medical inspectorate.

DR WILLIAM G PICKERING, MBBS, MRCP, MRCGP, AFOM, DCH, DRCOG

7 Moor Place, Gosforth, Newcastle upon Tyne NE3 4AL.

\section{Educating Competent and Humane Physicians}

Hugh Hendrie and Camille Lloyd, 223 pages, Indiana, US\$29.95, Indiana University Press, 1990

There is a common and justified belief that we are in danger of producing doctors who, whilst being good at the technical aspects of medicine, are not sufficiently caring about, and sensitive to, their patients' needs. The increasing concern with the teaching both of ethics and communication skills as part of the student curriculum is a welcome development in recent years. In Europe we are slowly following where North America leads. The development of medical ethics teaching has been largely at the instigation of philosophers, theologians and lawyers. In some places the syllabus develops from a consideration of real patients, in other places ethical principles are used as the starting point. In either case the content tends to be related closely to the concerns of moral philosophy.

If one were to ask why medical students should be taught ethics then I imagine that the final justification would be that such teaching is likely to help in producing better doctors. And better doctors would be doctors who are likely to be more caring of their patients, more sensitive to the moral aspects of medical practice.

This excellent book is not primarily about how one would teach medical ethics and communication skills. It goes straight to the issue of how students should be trained in order to maximise the chance that they become caring and humane doctors. The points that it raises complement any discussion of the teaching of ethics.

The 12 essays have been well chosen and edited so that the book as a whole has a structure and an argument. The argument starts with reviews of the evidence that social and psychologica factors are of great importance both in the aetiology and management of physically ill people. Doctors can improve management if they are able to understand the role these factors are playing and able to influence patients through good and sensitive communication. One of the pleasures in reading this book is finding interesting ideas sparkling from within the text. For example, to learn of the need for doctors to learn communication skills comes as no surprise, but the suggestion that doctors should teach patients how to communicate sets the mind thinking down new avenues.

The second part of the book looks at current medical education. Two important criticisms are made of current practice. The first is that medical training tends to emphasise excessively the very ill patient. Students learn to undervalue the importance of less severe illness, and they have little experience of long-term problems. General practitioners will recognise here one of the problems they experience with hospital-based medicine: the excessively optimistic accounts of an acute intervention which when seen in the context of the patient's longer-term welfare appears useless or even detrimental.

The second point is that if medical students are going to be caring of patients, then they themselves must be treated in a humane fashion. More generally this assertion can be expressed by saying that the relationship between the students and their teachers should mirror, in many ways, the relationship that should exist between doctor and patient. This view has important implications for the teaching of medical ethics for it suggests that we should be paying as much attention to the structures and relationships between teachers and taught, as we should to the actual content of our courses.

The last part of the book looks both at the past, and the future. Of particular interest with reference to the themes of the second part is the preliminary report of an intervention study carried out at the Memorial Sloan-Kettering Cancer Center. Essentially the intervention involved giving more help and support to the junior medical staff, and the preliminary results suggest this had a beneficial effect on patient care. This 
provides some empirical support for the belief that junior doctors should be cared for not only for their own sakes but also for that of their patients. I hope that this kind of evidence will speed up the day when junior doctors are valued and supported as they should be.

DR TONY HOPE, Oxford Practice Skills Project, Medical School Offices, John Radcliffe Hospital, Oxford.

\section{Who am I? Identity, Adoption and Human Fertilisation}

Christine Walby and Barbara Symons, 127 pages, London, £9.95, British Agencies for Adoption and Fostering, 1990

The Human Fertilisation and Embryology Act 1990 was fully implemented by the end of last year. The contention of this book is that the code of practice governing the Statutory Licensing Authority, and the regulations made by the Secretary of State, should be informed by knowledge gained from the closest parallel in human relationships - the adoption of children by substitute parents, involving the severance of legal ties with members of the biological family.

This booklet charts the historical development of adoption in our society, including the change of emphasis from adoption being regarded as largely a solution to the problems of adults to an emphasis on the importance of decisions being based on the best interests of the child. It also describes the process, the rationale and the dilemmas which have resulted in the shift in adoption philosophy and practice from confidentiality and secrecy being paramount towards carefully controlled access to information and increasing openness. It is heartening that this development stems from research and feedback from participants in adoption, not from abstract principles and unfounded assumptions. The issues which emerge are all highly relevant to the current debate about the ethics of human fertilisation by donor, and surrogacy for commissioning parents.

The authors demonstrate that the conflict between a 'laissez faire' attitude, and agencies taking some responsibility for decisions regarding fitness for parenthood, is of crucial significance. Reliable findings highlight the importance of a recognition of the difference between biological and other forms of parenthood. The denial of reality has been found to have an unfavourable impact on relationships within the family. The authors furnish sound arguments for formal selection procedures, which explicitly acknowledge the responsibilities to children, and the adults they will become, inherent in direct social or medical intervention to create families, and which signify an official refusal to collude with pretence. It may be inimical to the medical profession to make judgements regarding eligibility for 'treatment', but there is ample evidence that preparation for parenthood, especially when it involves the extra dimension associated with adoption or human fertilisation, confers lasting benefits. Although this should be seen primarily as an educative process, rather than a series of hurdles, adults who were adopted as children are clear that an assessment procedure should attempt to ascertain the state of mental and physical health of prospective parents, as well as the quality of the marriage or partnership, if one exists. Damaged individuals, or couples, are unlikely to be able to cope with the extra vulnerability inherent in the highly complex set of relationships established by adoption or donor fertilisation.

The authors also discuss the implications of 'genealogical bewilderment', a condition described by thousands of adopted people worldwide, whose formation of a sense of identity has been hampered by lack of information about their heredity. The establishment of a clear, integrated understanding of one's identity is a prerequisite for the development of healthy emotional and social maturity. This secure concept of self, based on acceptance and trust, can only be built on a foundation of honesty and knowledge. Living a lie will take its toll on parents and child alike. This places an obligation on practitioners to furnish parents with adequate, written information about a child's biological background, and to attempt to ascertain willingness and ability to communicate to the child about his or her origins.

Research indicates, however, that a requirement to explain the truth is not the same as making this possible or sufficient. The amount and accuracy of information, and an atmosphere of open communication, whereby the meaning and implications of having two sets of parents are reiterated and explored at appropriate stages, are critical. Research in the field of adoption has revealed that parents cannot be adequately prepared for the inherently painful and on-going task of explaining in advance. Help, in the form of skilled and experienced counselling, should be available, as an entitlement, subsequently. This raises the crucial question of continuing services for families which have been created as a result of sperm or embryo donation.

This lively, informative and lucid book provides convincing arguments for making a close comparison between the field of adoption and people conceived through human fertilisation techniques. It would be unethical to ignore the lessons gained from adoption about the need to balance the rights and needs of all the parties involved in those delicate transactions which involve transferring children from one set of parents to another.

DIANA REICH, Post Adoption Centre, 8 Torriano Mews, Torriano Avenue, London NWS $2 R Z$

\section{The Human Embryo: Aristotle and the Arabic and European Traditions}

Edited by G R Dunstan, 246 pages, Exeter, £25.00, University of Exeter Press, 1990

The jacket-illustration of this book depicts St Hildegard's vision of the ensouling of the human embryo. This vision draws on a tradition going back at least to Aristotle, in which the action of the male semen on the female menstrual blood at conception is compared to that of rennet on milk in cheese-making. Delightfully quaint, one might think, but hardly relevant to the questions so urgently raised by the Human Fertilisation and Embryo Act.

This collection of essays is published in the hope that past science is more than a dead letter. It traces some crucial moments in the tradition of enquiry into human reproduction, culminating in an admirably clear article on the embryo in contemporary medical science by Braude and Johnson, which takes care to emphasise points relevant to current ethical and social-policy debates. Ideally the reader interested in ethics will benefit from the other specialist 